\title{
O USO DAS TECNOLOGIAS DIGITAIS NO ENSINO DE GEOGRAFIA: INVENTÁRIO DE PRÁTICAS PUBLICADAS ENTRE 1999-2020 EM PERIÓDICOS DA ÁREA DE ENSINO
}

\author{
Sara Pimenta Lima ${ }^{1}$; Maria Gracilene de Carvalho Pinheiro²; Diego Fogaça \\ Carvalho $^{3}$
}

\begin{abstract}
${ }^{1}$ Secretaria de Educação Estado do Paraná. Professora de Geografia da Rede Estadual de Ensino do Estado do Paraná (SEED) e mestre em Metodologias para o Ensino de Linguagens e suas Tecnologias. sarapmnt@ gmail.com - ORCID: http://orcid.org/0000-0002-5118-7958

${ }^{2}$ Pós-doutora em Metodologias para o Ensino de Linguagens e suas Tecnologias da Universidade Pitágoras Unopar (UNOPAR). gracilenepinheiro@ gmail.com - ORCID: http://orcid.org/0000-0003-4240-5041

${ }^{3}$ Professor do Programa de Pós-Graduação em Metodologias para o Ensino de Linguagens e suas Tecnologias da Universidade Pitágoras Unopar (UNOPAR) e Mestrado em Ensino de Ciências e Matemática da Universidade Anhanguera Uniderp (UNIDERP). diegofocarva@ gmail.com - ORCID: http://orcid.org/0000-0002-4984-6344
\end{abstract}

Artigo recebido em 11/07/2020 e aceito em 09/04/2021

\begin{abstract}
RESUMO
Este artigo objetiva inventariar a produção científica publicada em periódicos avaliados pela CAPES, entre os anos 1999 e 2020, em extratos A1, A2, B1 e B2, que abordam o uso de tecnologias digitais no ensino de Geografia. Essa busca se justifica pela inquietação de conhecer quais tecnologias digitais foram utilizadas para ensinar Geografia no Brasil e publicadas em periódicos. Com base na Análise de Conteúdo, organizou-se um processo de busca de artigos por meio de palavras e expressões consideradas representativas, no caso, a confluência das palavras tecnologias e geografia. Na continuidade, os resumos dos artigos foram lidos, culminando no inventário analisado em que foram obtidos os recursos tecnológicos utilizados nas pesquisas que tomam como objeto de estudo o ensino de Geografia. Decorrente dessa análise, evidenciou-se a preocupação de pesquisadores com o ensino de Geografia mediado pelo uso de tecnologias digitais. Contudo, há ainda poucas vivências em contextos escolares, embora tenha havido um aumento nos últimos anos, caracterizando uma tendência. Tal constatação remete à necessidade de discussões, no âmbito da formação de professores, que lhes permitam apreciar essa perspectiva de ensino.
\end{abstract}

Palavras-chave: revisão sistemática; Ensino de Geografia; tecnologias digitais. 


\title{
THE USE OF DIGITAL TECHNOLOGIES IN TEACHING GEOGRAPHY: INVENTORY OF PRACTICES PUBLISHED BETWEEN 1999-2020 IN JOURNALS IN THE AREA OF TEACHING
}

\begin{abstract}
This paper aims to inventory the scientific production published in journals that are applied by CAPES between the years 1999 and 2020 in extracts A1, A2, B1 and B2 that mentioned the use of digital technologies in teaching Geography. This search is justified by the concern of knowing which digital technologies were used to teach Geography in Brazil, published in periodicals. Through inspirations in content analysis, a process of searching for articles was organized using words and expressions considered representative, in this case, the convergence of the word's technologies and geography. Subsequently, the abstracts of the articles were read, resulting in the analyzed catalog in which the technological resources used in the research that take the teaching of Geography as object of study were obtained. As a result of this analysis, the concern of researchers with the teaching of Geography was evidenced, mediated using digital technologies. However, there are still few experiences in school contexts, but there has been an increase in recent years, characterizing a trend. Such finding points to the need for discussions, in the context of teacher education, to enable them to appreciate this teaching perspective.
\end{abstract}

Keywords: systematic review; Geography Teaching; digital technologies.

\section{INTRODUÇÃO}

Este texto tem o objetivo de inventariar os artigos publicados em periódicos avaliados pela CAPES - Coordenação de Aperfeiçoamento de Pessoal de Nível Superior, no quadriênio 2013-2016, nos quatro maiores extratos - A1, A2, B1 e B2, que abordam o ensino de Geografia via tecnologias digitais. Este inventário se justifica pela necessidade de conhecer quais foram as práticas desenvolvidas e reportadas em artigos entre os anos 1999 e 2020, assim como as tecnologias digitais mobilizadas nessas práticas.

A seleção dos artigos teve como base a Análise de Conteúdo (BARDIN, 2016) e os procedimentos que visam à elaboração de filtros que localizam os artigos por meio de palavras, com respaldo em Passos (2009a); Passos (2009b); e Barbosa, Carvalho e Rizek (2013). Após a primeira seleção, os artigos foram lidos em sua íntegra e, em seguida, elaborou-se um quadro com o intuito de verificar se o texto se reportava ou não a uma prática de ensino de Geografia mediada por tecnologias digitais.

$\mathrm{Na}$ continuidade do artigo, apresentam-se as considerações teóricas referentes ao ensino de Geografia Física, enfatizando as aulas de campo. Nesse processo, descrevem-se os métodos 
utilizados, bem como os critérios elaborados na seleção dos artigos. Por último, são discutidos os resultados encontrados nos estudos analisados.

\section{ALGUNS APONTAMENTOS SOBRE A GEOGRAFIA E SEU ENSINO}

A Geografia é uma ciência que analisa os fatos a partir da observação, descrição e explicação dos fenômenos que ocorrem na natureza e na sociedade. Limita-se aos conteúdos abordados pela Geografia Física, por se acreditar que eles podem ser compreendidos mais profundamente com a realização de aulas de campo. Nesse sentido, faz-se necessário que o professor leve os alunos para o ambiente natural, externo ao ambiente escolar, com o objetivo de problematizar os fenômenos naturais e sociais considerando os conceitos da Geografia.

$\mathrm{Na}$ sala de aula, por outro lado, o professor enfrenta várias dificuldades para promover as aulas de campo, questões de ordem burocrática, financeira, bem como a vulnerabilidade dos alunos fora do ambiente escolar. Em consequência disso, o ensino da Geografia Física, que se baseia na observação, análise e explicação dos fenômenos endógenos e exógenos ocorridos na superfície, fica limitado à abordagem tradicional com foco no livro didático e realização de exercícios.

Diante desse contexto, defende-se o uso das tecnologias digitais como uma alternativa para a superação das limitações assinaladas, principalmente pela possibilidade de reconstruir situações próximas da realidade, o que permite a sua problematização.

No que se refere à relação entre sociedade e natureza, presentes na Geografia - o desenvolvimento do homem proporciona a relação entre a Geografia Humana e Física nas quais se configuram os diversos aspectos em estudo, por exemplo, a Climatologia; a Geopolítica; a Geomorfologia; a Cartografia; e a Ciência -, entende-se que a Geografia possui uma linguagem específica, que é necessário ensinar aos alunos desde seu ingresso na escola. Nesse sentido, sua maior contribuição é a leitura crítica dos diversos temas, pois a matéria-prima está na base das relações que configuram uma espacialidade temporal.

O ensino de Geografia necessita, portanto, que os discentes tenham uma base sólida que os conduza à compreensão da Geografia vista na teoria e vivida na prática. Nessa perspectiva, o uso de imagens, fotos, mapas, aplicativos que promovam a realidade aumentada, bem como softwares de simulação dos fenômenos naturais, pode favorecer a adoção de uma linguagem própria da Geografia, que, no ensino, proporciona inúmeras informações para análise, discussão 
e interpretações, conduzindo o aluno ao aprendizado por um viés crítico, como argumenta Somma (2003):

A capacidade crítica não se dá espontaneamente: é fruto de uma formação, de um "caminhar educativo". O hábito mental de atitude crítica é um modo de ser, de sentir e pensar adquirido. [...] a educação institucional e a formação em geografia têm de se afirmar em seu valor verdadeiramente significativo para o ser humano. É um desafio motivador tratar de diminuir a EAD entre os fins e a prática, pois essa brecha não é só fruto do erro [...], mas de uma opção funcional do profissional professor (SOMMA, 2003, p.164).

De acordo com essa autora, é necessário ao professor realizar uma ação reflexiva que o conduza à constante busca de elementos que possam facilitar o ensino. Para ela, o

[...] aluno que sabe compreender a realidade em que vive, que consegue perceber que o espaço é construído, [...] perceber que todos os homens, que a sociedade é responsável por este espaço, conseguirá estudar questões e espaços mais distantes e compreender, [...] ao construir o seu conhecimento estará aproveitando os conteúdos de geografia para a sua formação, para ser um cidadão no sentido pleno da palavra (SOMMA, 2003, p.164).

Com base nessa afirmação, o ensino de Geografia convida o professor a ir além da reprodução dos livros didáticos. Assim, ao refletir sobre a qualidade do ensino, é preciso remeter à formação do professor a partir de três pontos:

[...] a sociedade, a realidade do ensino fundamental e médio e a ciência. [...] O conhecimento científico, elaborado, é transformado em conteúdo pedagógico e, portanto, em recurso didático necessário à prática social desenvolvida no interior da escola (SOMMA, 2003, p.62).

Sendo a escola o espaço de construção do conhecimento formativo, faz-se pertinente que a ciência geográfica seja trabalhada de maneira a conduzir os estudantes na construção do conhecimento geográfico. Nesse cenário, recomenda-se utilizar as tecnologias digitais como suporte a um novo olhar para o ensino e a aprendizagem das diversas temáticas. $\mathrm{O}$ uso desses recursos, aliado a uma metodologia de

pesquisa como princípio pedagógico, [possibilita]que o estudante possa ser protagonista na investigação e na busca de respostas em um processo autônomo de (re)construção de conhecimentos (BRASIL, 2012, p. 4).

Conforme afirma Somma (2003, p. 103),

Uma educação que contribua para o desenvolvimento do aluno deve atuar no processo de ensino e aprendizagem na perspectiva da construção do conhecimento, refletindo sobre a realidade vivida pelo aluno. 
Ao refletir nas palavras do autor, interpreta-se que o ensino da Geografia tem potencial para contribuir com esse processo de construção do conhecimento, levando o aluno a se perceber como integrante ativo na reconstrução do espaço geográfico.

A recomendação para o uso de recursos tecnológicos no ensino de Geografia é apontada em outros documentos oficiais de educação. Os Parâmetros Curriculares Nacionais de Geografia (BRASIL, 1998) sinalizam a inclusão de recursos tecnológicos no ensino, considerando-os como veículos de diferentes códigos de significação, de meios gráficos, audiovisuais e multimídias que projetam uma ampla socialização do conhecimento e da aprendizagem da ciência geográfica. Assim, os estudantes podem compreender os conteúdos específicos por meio desses diversificados recursos.

A educação vem incorporando novas formas de tornar as ciências compreensivas às diferentes faixas etárias do ensino, e as tecnologias digitais são um instrumento que auxilia o professor na condução das aulas e que lhe permite construir ambientes propícios para que o aluno tenha uma aprendizagem crítica.

Assim, inventariar a produção científica que se reporta às práticas realizadas em sala de aula que utilizaram tecnologias digitais, e identificar quais foram essas tecnologias, refere-se a abordar uma problemática pertinente para a área do ensino de Geografia, principalmente, por possibilitar um panorama de como as tecnologias digitais estão sendo utilizadas na área. Isso poderá ser fonte de inspirações para os desdobramentos em relação ao uso das tecnologias digitais no ensino de geografia.

\section{PROCEDIMENTOS METODOLÓGICOS}

Nesse contexto investigativo, optou-se pela pesquisa qualitativa, principalmente, por não se ter a intenção de refutar hipóteses (MORAES; GALIAZZI, 2011), mas de olhar minuciosamente os recursos tecnológicos utilizados para ensinar geografia no contexto dos artigos selecionados.

Inspirado nos procedimentos já realizados por Passos (2009a); Passos (2009b); e Barbosa, Carvalho e Rizek (2013), decidiu-se por um conjunto de palavras representativas que possibilitariam encontrar artigos que viessem ao encontro dos objetivos desta pesquisa. Assim, compreende-se que as palavras "tecnologias" e "geografia" se configuram representativas para as produções científicas que se queria inventariar, principalmente a confluência de ambas. 
Realizou-se uma busca na Plataforma Sucupira e foram encontrados os nomes e o ISSN de trezentos e cinco periódicos em Língua Portuguesa avaliados nos quatro maiores extratos A1, A2, B1 e B2 - da Área de Ensino no quadriênio 2013-2016. Esses extratos foram elaborados pela CAPES com o intuito de avaliar a qualidade dos periódicos nacionais e internacionais de cada área do conhecimento, sendo denominados Qualis-Periódico. Em suma, refere-se a um ranking que varia de A1 - maior avaliação -, A2, B1, B2, B3, B4, B5 e C menor avaliação - de acordo com listagens de critérios que cada área de conhecimento elaborou.

Em seguida, criou-se uma planilha, com o auxílio do software Excel, com as informações obtidas na plataforma e acrescidas do endereço do site no qual o periódico está hospedado. Com essas informações em mãos, iniciou-se o processo de busca, explorando cada uma das páginas e pesquisando artigos que contivessem as palavras tecnologias e geografia. Nesse primeiro momento, foram encontrados 90 artigos.

Em um segundo momento, realizou-se a leitura dos resumos e de fragmentos dos artigos, com o intuito de reunir os textos que abordavam práticas no ensino da geografia, da Educação Básica ao Ensino Superior. Dos 90 artigos, 47 foram descartados por abordar análise de currículos, reflexões voltadas às estruturas de cursos de formação de professores de geografia ou abordar as tecnologias de forma teórica, apresentando possibilidades. Os 43 artigos restantes foram lidos na íntegra com o objetivo de identificar o recurso tecnológico mobilizado em cada contexto de ensino e aprendizagem de geografia

\section{DESCRIÇÃO E ANÁLISE DOS DADOS}

Reitera-se que, com o objetivo de conhecer os recursos tecnológicos utilizados para ensinar Geografia, foram selecionados artigos publicados em periódicos da Área de Ensino com Qualis A1, A2, B1 e B2 - quadriênio 2013-2016 -, que apresentavam, no corpo do texto, a confluência de palavras representativas, no caso: "tecnologias" e "geografia".

Em um primeiro momento da análise, cabe esclarecer o espaço temporal delimitado nesta investigação. O ano de 2020 justifica-se como limitante superior por ser, até a escrita deste artigo, o último ano em que os periódicos finalizaram suas publicações. O limitante inferior, 1999, refere-se ao ano de publicação do primeiro artigo selecionado após a aplicação dos filtros de seleção. 
Na sequência, é apresentado o Gráfico 01 que contempla a distribuição dos 43 artigos ao longo de cinco quinquênios de publicação, ou seja, vinte e cinco anos.

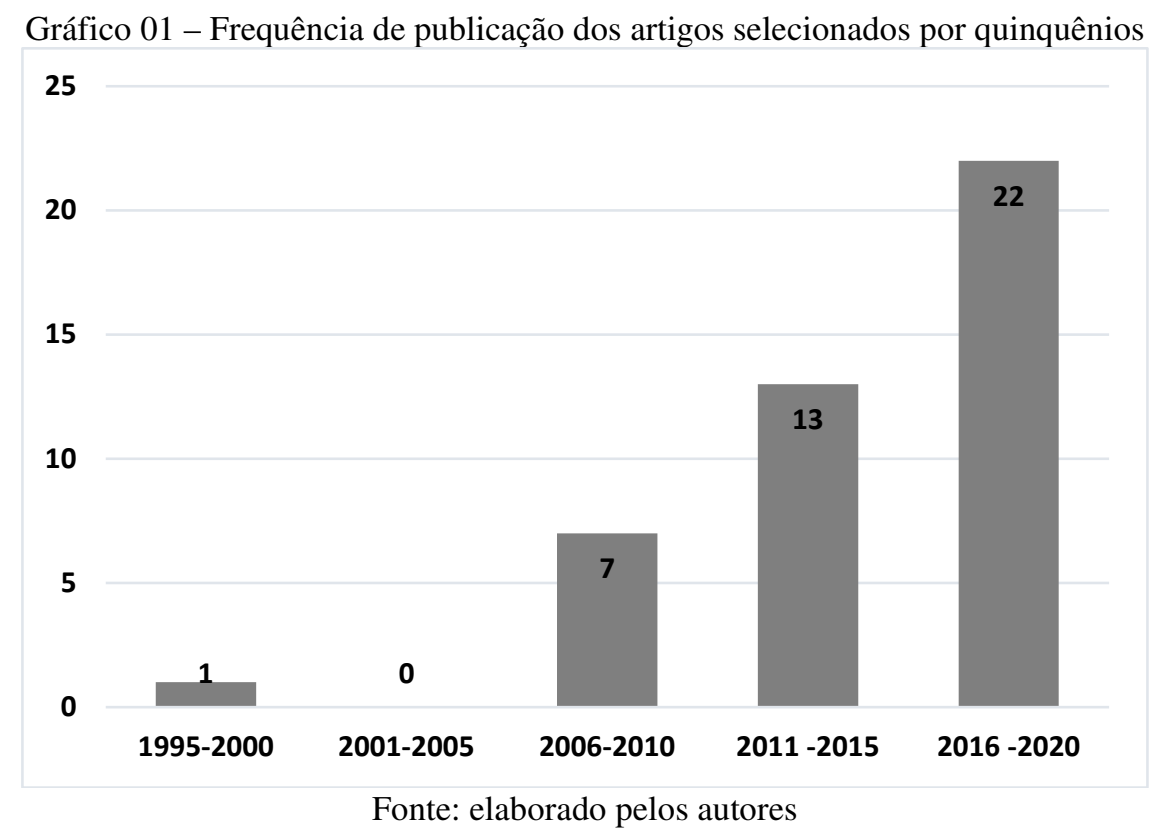

Pode-se observar, de acordo com o gráfico, que, no quinquênio 1995-2000, tem-se a publicação de um artigo. Entre 2001 e 2005, não se identificou nenhuma publicação. No quinquênio 2006-2010, houve a publicação de sete artigos. Entre 2011 e 2015, têm-se treze publicações e, no último quinquênio, 2016 - 2020, tem-se a publicação de vinte e dois artigos.

Compreende-se que, nos últimos cinco anos, houve um aumento de publicações a respeito da utilização de tecnologias no ensino de geografia com enfoque nas situações do cotidiano da sala de aula, incluindo Educação Básica, Ensino Técnico e Ensino Superior. Para estruturar a análise dos textos selecionados, optou-se por organizá-la diante do quadriênio com ênfase no recurso tecnológico digital utilizado. Outra justificativa que pode ser atribuída a essa escolha é a evolução tecnológica que aconteceu durante esses anos, fator que influenciou diretamente a produção de artigos que interessam a esta investigação, principalmente pelo aumento do acesso da população brasileira aos recursos tecnológicos, ou seja, a popularização das tecnologias digitais. 


\section{$1^{\circ}$ e $2^{\circ}$ Quinquênios [1995- 2000] e [2001 - 2005]}

Considerando esses quinquênios, destaca-se a publicação de um artigo, que data de 1999. Trata-se de uma proposta que utilizou jogos de simulação em salas de aulas, para cuja execução é imprescindível a participação coletiva. Aguiar (1999) apresentou três opções de jogos didáticos a serem utilizados nas aulas de geografia. Dentre eles, estão os jogos de tabuleiro, jogos de representação e os jogos para computador, que iriam simular situações reais que poderiam ser problematizadas no processo de ensino e aprendizagem.

A proposta da pesquisa centra-se na divulgação dos jogos, mas pode-se interpretar, em consonância com as tecnologias digitais da época, a limitação da utilização de softwares instalados nos computadores nos laboratórios de informática das escolas e a conexão via internet, que não foi mencionada.

\section{$3^{\circ}$ Quinquênio [2006- 2010]}

Nesse quinquênio, identificou-se a publicação de sete artigos: três em 2008, dois em 2009 e um em 2010. Interpreta-se que houve dois extremos na utilização desses recursos. De um lado, estão as tecnologias digitais em sua forma domesticada, ou seja, elas são utilizadas de forma a substituir práticas já realizadas via tecnologias analógicas, não havendo mudança na forma de estruturar o pensamento (BORBA; SILVA; GADANIDIS, 2015). Para exemplificar, pode-se destacar o uso de filmes em DVD e a televisão. De outro lado, tem-se a Internet adentrando os cenários das investigações e a produção de objetos de aprendizagem, específicos para o processo de ensino e aprendizagem da geografia, tecnologias digitais que se popularizarão nos quinquênios seguintes. Na sequência, apresenta-se uma síntese de cada estudo encontrado.

O estudo desenvolvido por Amorim (2008) teve como participantes professores de Geografia. Foi proposto um curso fundamentado em três bases: percepção geográfica; ensino da Geografia pautado na Lei 9394/96 e Parâmetros Curriculares Nacionais (PCNs) e Internet como meio de ensino, aprendizagem e divulgação científica no campo da Geografia. Assim, de acordo com Amorim (2008), o estudo discutiu a validade do Museu Virtual de Jacobina (BA) como meio de ensino, aprendizagem e divulgação científica e proporcionou aos participantes experiências didáticas e a identificação de possibilidades pedagógicas do Museu Virtual, que 
se tornou material didático. Girordani, Bezzi e Cassol (2008) utilizaram o objeto de aprendizagem Decifrando os Mapas, que foi aplicado na quinta série do Ensino Fundamental. Esse objeto de aprendizagem mostrou aos alunos os principais elementos que compõem um gráfico, possibilitando-lhes práticas de simulação e tornando-os mapeadores.

Dornelles et al. (2008) mostraram a importância do uso das geotecnologias no Ensino Médio e a sua contribuição para o desenvolvimento de competências básicas. As principais ferramentas utilizadas foram o Sistemas de Informação Geográfica - GIS/SIG, o Sistema de Análise GeoAmbiental - VistaSAGA/UFRJ e o PowerPoint, além de outros recursos da Internet, como o Yahoo! Brasil Grupos e WebQuests. Os autores subdividiram a apresentação em dois módulos distintos: o Teórico e o Prático. O Teórico, com duração de duas a três semanas, presencial ou semipresencial, envolveu conceitos de Geoprocessamento e SIG; o Prático, com duração de duas semanas, envolveu o manuseio do programa VistaSAGA.

Ostrovski e Ostrovski (2009) utilizaram um filme como recurso tecnológico, que enfatizou os seguintes conceitos no processo de reflexão: grupos étnicos, desigualdade social, ferrovias. Dornelles (2009) destacou a importância das técnicas e a utilização do SIG/GIS Sistema de Informação Geográfica, aplicado no ensino de Geografia, nos ensinos Fundamental e Médio. Os principais sistemas utilizados foram: VistaSAGA/UFRJ, SISPLAMTE 5as com GIS v1. 0/S-.9, SPRING/INPE e MapServer. Cavalcante e Farias (2010) mostram como o uso dos recursos tecnológicos, computadores, som, televisões, DVD e a própria Internet, consegue ampliar a proposta de ensino e de aprendizagem para os alunos.

Para finalizar esse quinquênio, Santos Júnior e Lahm (2010), por meio da categorização de imagens de satélite do Google Earth e por canal analógico de sensoriamento remoto, levaram estudantes do Ensino Médio a analisarem mapas mentais da imagem do lugar onde viviam, que eles mesmos desenharam, e mapas em imagens de satélites (software Google Earth ${ }^{\mathrm{TM}}$ ), sobre os quais eles também se expressaram, posteriormente, de forma escrita.

\section{$4^{\circ}$ Quinquênio [2011-2015]}

Durante os anos de 2011 a 2015, foram publicados treze artigos, um pouco mais que o dobro do quinquênio anterior. Em 2012 e 2014, foram encontrados quatro artigos em cada ano, e, em 2015, cinco artigos. Em síntese, pode-se enunciar as seguintes tecnologias como as mais 
utilizadas: 1 - Moodle; 2 - Filmes e produção de vídeo; 3 - Objetos de Aprendizagem; 4 Aplicativos; 5 - Redes Sociais.

Barin, Liziany e Ellensohn (2012) realizaram uma pesquisa sobre o uso do Moodle nas área de humanas e exatas. De acordo com os autores, foi possível notar que a utilização do Moodle possibilitou a construção de interatividade, interação, colaboração e autonomia para os alunos. O estudo desenvolvido por Macêdo, Silva e Melo (2012) consistiu em uma atividade de extensão universitária com estudantes do curso de Magistério. Nessa atividade, foram utilizados cartas topográficas, mapas e plantas, software Google Earth, jogos lúdicos. O objetivo do uso desses recursos era proporcionar aos estudantes do Magistério conhecimentos e experiências no estudo e aprendizagem acadêmica da Geografia, assim como o conhecimento dos recursos disponíveis na Internet e a forma como podem ser utilizados em aulas com alunos dos anos iniciais.

A pesquisa de Perinelle-Neto e Paziani (2012) traz a aplicabilidade dos curtas-metragens nos cursos de História e Geografia. Os autores propõem que, a partir da utilização do cinema como um grande recurso tecnológico, os alunos de graduação possam descrever em curtasmetragens assuntos ligados ao seu cotidiano, ao seu presente e ao local onde vivem. Esse tipo de tecnologia agregará muito ao aprendizado em sala de aula, pois ele possibilitará a reprodução, em vídeo, da realidade de cada um dos alunos, de forma a expor a real situação local, propondo melhorias na região onde vivem.

Rovani et al. (2012) desenvolveram dois objetos - simuladores - de aprendizagem lúdicos e interativos para uso nas aulas de Educação Básica, visando contribuir para o ensino e a aprendizagem de conceitos da geografia, como relevo e bacias hidrográficas. Para tanto, os autores utilizaram os softwares ArcGis 9.3, no módulo ArcMap, o Photoshop e o Flash. A partir dessa experiência, os autores concluíram que o ensino e a aprendizagem de conceitos da Geografia podem ser favorecidos com o uso de objetos de aprendizagem interativos e inovadores.

Em sua pesquisa, Oliveira e Kunz (2014) utilizam a produção de vídeo como mediação tecnológica no conteúdo solicitado pelo professor aos alunos. Assim, os alunos podem utilizar mais de uma forma de aprender, indo além da visualização do conteúdo e da prática, o que lhes possibilita mais recursos para ter um aprendizado mais eficaz. Lima, Oliveira e Mesquita (2014) destacam que o Google Maps é uma ferramenta produtiva no ensino de geografia, pois os alunos investigados apresentaram facilidade em aprender e também na interação entre eles. Para os 
autores, as novas formas de se compreender cartografia, nesse caso, utilizando o Google Maps, facilitam o aprendizado.

O estudo realizado por Oliveira e Mesquita (2014) teve por objetivo proporcionar aos alunos maiores conhecimentos acerca da cartografia. Os autores utilizaram como ferramentas aplicativos com os quais os alunos já possuem grande familiaridade, por exemplo, Google Earth, Google Maps, Mapas Digitais, Bússola e o Sistema de Posicionamento Global (GPS). De acordo com os autores, as tecnologias contribuíram aumentando consideravelmente o engajamento dos alunos no processo de ensino e aprendizagem.

Silva e Soltau (2014) apresentam como alternativas para o processo de ensino e aprendizagem a utilização de jogos on-line interativos e o uso das redes sociais. A tarefa proposta referiu-se à mediação da circunferência da terra, envolvendo várias disciplinas. Os autores destacam que a participação dos alunos foi exitosa e o contexto de aprendizagem constituído fomentou a interdisciplinaridade entre Geografia, História e Matemática.

O estudo desenvolvido por Borges (2015) foi realizado com alunos dos anos finais do Ensino Fundamental e explorou questões relacionadas ao impacto da agroindústria no estado de Goiás. Com o uso de celulares, os alunos filmaram tudo o que observaram que estava relacionado à temática em discussão e realizaram entrevistas com moradores. Ao final, os estudantes participaram do debate das produções dos vídeos. Sobre os resultados da metodologia adotada no estudo, a autora afirmou que utilizar vídeos como recurso pedagógico, associados às vivências dos alunos, é uma forma inovadora e motivadora no ensino de Geografia.

O artigo de Barin; Ellensohn; e Botega (2015) apresenta uma pesquisa desenvolvida com estudantes do curso de Licenciatura em Geografia no ambiente virtual de aprendizagem Moodle. O estudo aponta que o uso dos recursos tecnológicos, como vídeos, Google Earth e Internet, tem ocorrido de forma significativa. Além disso, os autores argumentam que o uso das TIC possibilita ampliar a base de recursos didáticos e impulsiona o interesse dos estudantes do curso de Geografia em flexibilizar os procedimentos de ensino, visando à construção de conhecimentos sólidos da Geografia.

Perinelli -Neto e Paziani (2015) destacam a importância dos curtas-metragens na formação dos alunos em licenciatura nos cursos de História e Geografia. Os autores mencionam que o uso da tecnologia audiovisual pode fortalecer a construção de novos conhecimentos de sobre aprendizado dos alunos que estariam prestes a ingressar no corpo docente. Oliveira, 
Buffon e Werlang (2015) relatam a dificuldade do aluno em visualizar a dinâmica da geada e do orvalho, pois a abordagem nos livros didáticos se dá de forma estática. Visando superar esse fato, os autores utilizam os Objetos de Aprendizagem como elo entre as mídias e o ensino da climatologia. De acordo com os autores, a utilização de OA tornou as aulas mais atrativas, cativando a atenção dos alunos nas realizações das atividades, permitindo, assim, maior contribuição na aprendizagem do discente e facilidade ao docente em expor o conteúdo de uma forma que seja compreendido pelo aluno.

Bona (2015) apresenta, como alternativa de aprendizagem, o uso da rede social Facebook como forma de interação dos alunos do $8^{\circ}$ ano do Ensino Fundamental com os docentes, através de grupos de estudos virtuais. O grupo constituiu-se um espaço para a disponibilização de conteúdos complementares aos conteúdos apresentados em sala de aula.

\section{$5^{\circ}$ Quinquênio [2016-2020]}

Nesse quinquênio, referente aos últimos cinco anos, tem-se a maior concentração de publicações, vinte e dois artigos, distribuídos da seguinte maneira: no ano de 2016, foi publicado um artigo; em 2017, seis; em 2018, cinco; em 2019, dois e, em 2020, oito. As tecnologias digitais mobilizadas também variam, indo da utilização de vídeos e documentários, passando pela utilização de video games, smartfones, objetos de aprendizagem, aplicativos populares da Google, realidade aumentada, tecnologias de georreferenciamento, podcast e a própria Internet como fonte de pesquisa.

Silva (2016) realizou uma revisão bibliográfica sobre a estrutura e o funcionamento dos jogos eletrônicos - gamestudies - e das investigações dos video games desenvolvidos na área de Ciências Humanas, com destaque para a Geografia. A partir da interação direta do objeto de estudo - os games - com as comunidades virtuais de jogadores, foi possível notar, de acordo com o autor, diversas possibilidades de tratamento dos jogos eletrônicos, sobre as quais ele discutiu a partir das seguintes categorias: importância da espacialidade e dinâmica espacial nos videogames; como os lugares reais são representados; vivência dos lugares; produção e consumo de um imaginário geográfico; representações sociais; processos, conceitos e fenômenos representados e papéis desempenhados pela paisagem nos jogos (SILVA, 2016).

Medeiros (2017) apresentou as experiências do projeto Tecnologias digitais e Geografia. Trata-se de um projeto vinculado ao PIBID - subprojeto de Geografia de uma universidade 
pública do Rio Grande do Norte. De acordo com o autor, o projeto foi desenvolvido com o objetivo de despertar o interesse dos graduandos para o uso das tecnologias digitais no processo de aprendizagem da Geografia. Assim, refletiu nos limites e possibilidades do uso da informática na atividade docente dos professores de geografia.

Em seu estudo, Ferreira e Leite (2017) descrevem a necessidade da utilização das geotecnologias em cinco escolas estaduais na cidade de Montes Claros - MG. As atividades realizadas referem-se a uma breve apresentação dos conceitos e utilização das geotecnologias e softwares para a prática cartográfica. Os autores reforçam que a aplicabilidade dessas tecnologias trará facilidades para o processo de aprendizado dos alunos. Todavia, para o sucesso das atividades, é de suma importância que o acesso dos alunos aos recursos tecnológicos seja garantido.

A pesquisa realizada por Rizzatti et al. (2017) contemplou o ensino do relevo por meio de recursos geotecnológicos e cartográficos, por exemplo, o QGIS, em um sexto ano do Ensino Fundamental. Os autores destacam que a utilização desses recursos contribuiu para o desenvolvimento do interesse dos alunos, bem como os auxiliou no entendimento da realidade que os cerca.

Herpich, et al. (2017) apresentaram uma atividade de orientação - frequentemente utilizada como uma prática pedagógica no ensino de Geografia -, que auxiliou nos processos de ensino e de aprendizagem de Geografia por meio da realidade aumentada (RA). Assim, estudantes do $6^{\circ}$ ano do Ensino Fundamental utilizaram um aplicativo que foi construído pelos pesquisadores com o software Unity para a plataforma Android, em que eles, os estudantes, puderam explorar conhecimentos referentes a tópicos de cartografia, pontos cardeais e localização geográfica. Os resultados evidenciaram que a atividade de orientação, associada ao uso de acessórios tecnológicos, colaborou com a visualização do conteúdo e permitiu que os alunos estabelecessem relação entre a teoria e a prática.

A pesquisa de Oliveira (2017) traz o uso das Tecnologias Digitais de Informação e Comunicação (TDIC) como um processo de aprendizagem para os alunos no ensino da disciplina de Geografia. A proposta visa integrar o uso desses recursos nas escolas federais, utilizando como ambiente de aprendizado o próprio laboratório de informática das instituições. Os primeiros alunos a utilizarem esses recursos tecnológicos na disciplina de geografia foram todos os alunos das primeiras turmas. As tecnologias proposta pelo autor são a Webcartografia, ferramentas on-line em que é possível criar mapas e o uso do Cloud Computing, que nada mais 
é que um gerenciador de armazenamentos de dados em nuvem. Com isso, acredita-se que os alunos estarão mais motivados a participarem de forma ativa das atividades em sala de aula.

Votto e Rodrigues (2017) analisaram a utilização de filmes como proposta metodológica para o ensino de Geografia. Como resultado dessa análise, concluíram que o trabalho com filmes possibilitou explorar temas e conceitos de forma lúdica, auxiliando no aprendizado da Geografia. Advertem, porém, sobre o papel do professor: cabe a ele levar o aluno a perceber o sentido e a utilização de filmes como recurso didático que conduz ao conhecimento e à compreensão do mundo em que vive, bem como as transformações econômicas, culturais, sociais ou físico-naturais no lugar onde mora e em lugares mais distantes (VOTTO; RODRIGUES, 2017, p. 222).

A pesquisa elaborada por Costa, Duailibe, e Bottentuit-Junior (2018) revela uma análise a partir da utilização e aplicação do Plickers no ensino de Geografia. Para a realização dessa pesquisa, foi feita uma experimentação envolvendo alunos do $9^{\circ}$ ano. O Plickers é um aplicativo que pode ser instalado tanto no Android como também no IOS. Os autores ressaltam que a praticidade em adquirir esse app é grande, levando em consideração que também é gratuito e permite ao professor a coleta de respostas da turma de maneira rápida e dinâmica. A partir dos dados coletados via observação sistemática e aplicação de questionários, os autores constatam que o uso do Plickers foi positivo, pois contribuiu para o despertar do interesse e engajamento dos alunos.

Para demostrarem a eficácia de um objeto de aprendizagem na disciplina de geografia, exclusivamente para os alunos do $5^{\circ}$ ano do Ensino Fundamental, Carvalho et al. (2018) apresentaram a aplicação de um objeto de aprendizagem, na qual foram utilizadas avaliações para dois grupos de alunos: grupo controle e grupo experimental. O experimental executou suas atividades juntamente com os professores no laboratório de informática, e o grupo controle, em sala de aula. De acordo com os autores, o grupo experimental apresentou maior rendimento no processo de avaliação em relação ao controle, o que pode indicar que a utilização dos recursos digitais contribuiu no processo de aprendizagem dos conteúdos avaliados.

Trentin e Scolaro (2018) apresentaram em seu artigo, Ensino interdisciplinar das projeções cartográficas e suas relações com a matemática através de podcasts, uma alternativa para de a aprendizagem em sala de aula, a utilização de podcasts. O estudo baseia-se na utilização de projeções cartográficas com o auxílio de planificações e cálculos matemáticos. A turma escolhida para a prática foi a de es alunos que cursam o $8^{\circ}$ ano do Ensino Fundamental. 
Todos tiveram que responder os questionários para informar o que eles acharam da utilização de podcasts nas aulas de geografia, que mostrou ser um recurso viável para o processo de aprendizagem dessa disciplina.

Como forma de ampliar o processo de ensino e aprendizagem através do uso da tecnologia, Ferreira e Couto-Junior (2018) apresentam um trabalho totalmente voltado para jovens alunos do sétimo ano do Ensino Fundamental em uma escola da rede pública de ensino, localizada no estado do Rio de Janeiro. A proposta dos autores foi demonstrar o quanto é importante a realização de oficinas na escola, fundamentadas em Bakhtin, juntamente com a utilização das tecnologias digitais. Por meio do uso de smartphones como recurso tecnológicos, os alunos puderam elaborar textos descrevendo melhor a abordagem histórico-cultural de suas respectivas cidades.

Medeiros et al. (2018) desenvolveram um estudo de caso, sob abordagem qualitativa, referente à utilização do Google Maps no ensino de geografia, com o objetivo de apresentar essa ferramenta aos alunos, ensinando suas funções. As atividades realizadas pautaram-se pela conservação ambiental. De acordo com os alunos, o aplicativo contribuiu para o dinamismo nas aulas, facilitando a aprendizagem.

Ruis, Tamariz e Batista (2019) discutiram o uso dos móbiles games de entretenimento em atividades interdisciplinares. De acordo com os autores, os mobiles games, utilizados de maneira pedagógica, são viáveis para o ensino, principalmente por enfatizar sua forma dinâmica, levando o aluno a ter uma visão geral dos conceitos e, em alguns casos, específicos.

Em Metodologias ativas nas aulas de Geografia no Ensino Médio como estímulo ao protagonismo juvenil, Pereira, Kuenzer e Teixeira (2019) trazem um estudo referente ao uso das tecnologias no ensino de geografia. Como conclusão, os autores entendem que usar as tecnologias digitais de informação e comunicação como mediadoras em processos de ensino e aprendizagem de geografia promove uma aprendizagem mais significativa, pois é um método que proporciona aos estudantes maior participação, envolvimento e interação com o conteúdo.

Em Objetos de aprendizagem: instrumentos para a avaliação formativa em educação a distância, Francisco e Braga (2020) destacam que essas tecnologias são detentoras de um imenso potencial de fomentar, no processo de ensino e aprendizagem, a avaliação formativa. Nessa pesquisa, foram desenvolvidos dois Objetos de Aprendizagem para serem aplicados em cursos superiores de Geografia e Gestão Ambiental. A utilização das tecnologias tornou as aulas mais atrativas, promovendo a motivação dos alunos nas realizações das atividades. 
Em "Aprendendo fazendo": Cartografias: Relatos de experiências através da extensão universitária, Santos et al. (2020) buscaram usar ferramentas tecnológicas, como o uso da geotecnologia, para ensinar alunos do Ensino Fundamental, principalmente crianças, a como elaborar mapas virtuais por meio do uso de computadores e programas. Utilizaram como recursos os aplicativos webcart beta, SIEG Mapas e IPEA data e IBGE mapas.

No artigo Tecnologias móveis e leitura de mapas digitais nas séries finais do ensino fundamental, Karwoski e Gracioli (2020) chegaram à conclusão de que a utilização de mapas digitais no ensino de geografia, intermediados pelo uso de laptop e data show, causaram impactos no processo de ensino, influenciando positivamente o aprendizado dos alunos, pois há várias possibilidades de utilização das tecnologias. Além desse impacto positivo, foi constatado também o aumento do índice de engajamento dos alunos ao pesquisarem sobre o tema em foco na Internet, que também incide diretamente na aprendizagem.

Martins-Junior, Estevão e Martins (2020) utilizam o aplicativo Google Earth no ensino da Geografia, porque essa ferramenta apresenta uma série de possibilidades e potencialidades que contribuem para deixar o ensino de geografia mais atrativo, permitindo aos alunos tanto uma visão local como global através de mapas e imagens de satélites, de uma maneira interativa que possibilita ao aluno controle sobre a visualização e que ele aplique zoom para qualificar sua visão sobre determinada área. O Google Earth fornece uma riqueza de conteúdo, que, através da percepção visual, permite aos utilizadores analisar virtualmente o espaço geográfico.

Schuck, Cazarotto e Santana (2020) desenvolveram um estudo sobre as Tecnologias Digitais de Informação e Comunicação (TDIC) no ensino de Geografia. Os autores aplicaram um questionário em escolas públicas e constataram que não havia wi-fi, que a sala de informática e o data show estavam fora de uso. Os respondentes também destacaram a insatisfação de não ter acesso a essas tecnologias no processo de ensino e aprendizagem da geografia.

Ladeira (2020) relatou a exibição do documentário "Derrubaram o Pinheirinho", a que assistiram através do YouTube, como prática pedagógica no ensino de Geografia com alunos do Programa de Integração da Educação Profissional ao Ensino Médio (PROEJA). O intuito era estudar assuntos fundamentais para a compreensão da produção do espaço urbano. A utilização desse documentário, além de permitir aos alunos maior compreensão do conteúdo de geografia, também causou uma reflexão sobre as desigualdades presentes na sociedade. 
O artigo "O Jogo Street Fighter II como Possibilidade de Análise da Paisagem Geográfica no Ensino de Geografia" é uma revisão bibliográfica elaborada por Silva (2020), que destaca a contemporaneidade dos jogos, que cada vez mais se fazem presentes no dia a dia, principalmente entre os jovens e adolescentes. Pensando dessa forma, a autora ressalta a possibilidade de utilização de jogos no ensino de geografia, especificamente na análise da paisagem geográfica.

O estudo realizado por André e Santos (2020) utilizou como meio de ensino de geografia o YouTube, dinamizando o ensino, fazendo com o que o aluno chegue mais próximo do conteúdo, com imagens e sons. Como resultado da utilização do YouTube, fez-se notória a possibilidade dessa ferramenta como aliada do processo de ensino e aprendizagem, além de fomentar a criatividade e a curiosidade dos alunos.

\section{CONSIDERAÇÕES FINAIS}

Neste estudo, composto por um inventário, foi possível perceber que alguns pesquisadores têm demonstrado preocupação com o ensino de Geografia, apontando possibilidades de enriquecê-lo usando tecnologias digitais. Contudo, considera-se que as experiências proporcionadas aos professores, particularmente no Brasil, ainda são poucas, dada a importância da temática em discussão. Disso decorre a necessidade de investimentos tanto em estudos que exploram tal perspectiva de ensino da Geografia como na formação inicial e continuada de professores, de modo que os recursos digitais façam parte do métier dos professores e se efetivem como um meio de aprendizagem no contexto escolar.

Ressalta-se que, com a pesquisa à qual se integra este estudo de revisão, a primeira autora desenvolveu um estudo que vislumbra uma perspectiva de ensino de Geografia por meio de tecnologias digitais. Assim, sob a orientação do terceiro autor e coorientação da segunda autora, ela elaborou duas propostas para o ensino de Geografia Física, inspiradas nos jogos RPG, nas Sequências Didáticas e nas Trajetórias Hipotéticas de Aprendizagem, abordando os conceitos de relevo, vegetação e clima. A proposta assumiu características de uma metodologia que pode ser utilizada pelos professores em qualquer contexto da Geografia, necessitando de um cenário natural, como o litoral ou as montanhas, e de muita imaginação para que, durante a viagem, muitas situações sejam problematizadas e contribuam para a formação de conteúdos conceituais, procedimentais e atitudinais. 
Nesse sentido, reitera-se que revisões sistemáticas, como a realizada neste artigo, contribuem para se pensar no que até então se produziu sobre o uso de tecnologias digitais no ensino de geografia, destacando as lacunas, para, posterior a uma reflexão, direcionar futuras pesquisas que promovam cada vez mais a institucionalização dessas tecnologias digitais na Educação Básica em âmbito nacional.

\section{AGRADECIMENTOS}

À Coordenação de Aperfeiçoamento de Pessoal de Nível Superior - Brasil (CAPES) - Código de Financiamento 001.

À Fundação de Amparo de desenvolvimento do Ensino Superior Privado (FUNADESP).

Aos estudantes Willian Chagas e Wallace Junqueira pela contribuição na atualização do banco de dados.

\section{REFERÊNCIAS}

AGUIAR, V. T. B.; Jogos de simulação no ensino de geografia. Ensino em Re-vista, Uberlândia, v. 7, n. 1, p. 7-13, 1999.

AMORIM, E.S. M S. A internet no campo da geografia: a implantação do museu virtual de Jacobina-BA. Revista de Ensino, Educação e Ciências Humanas, n. esp., v.9, 2008.

ANDRÉ, I. R. N.; SANTOS, G. L; Vivendo o tempo atmosférico: O YouTube como ferramenta pedagógica no ensino de geografia. Revista Científica Eccos, São Paulo, n. 55, p. 1-12, 2020.

BARBOSA, L. N. S. C. de; CARVALHO; ELIAS, H. R. Educação no campo nas 10 edições do Encontro Nacional de Educação Matemática: uma retrospectiva. In: Encontro Nacional de Educação Matemática, 11, 2013, Curitiba - PR. Anais... Curitiba: PUCPR, 2013. p. 1-15.

BARDIN, L. Análise de Conteúdo. São Paulo: Edições 70, 2016.

BARIN, C. S.; ELLENSOHN, R. M.; BOTEGA, M. P. Uso e apropriações de recursos da tecnologia como elemento flexibilização no ensino-aprendizagem de geografia. Revista Novas Tecnologias na Educação, Porto Alegre, v. 13, n. 1, p. 1-10, 2015.

BARIN, C. S.; MULLER, L.; ELLENSOHN, R. M.; Construção de significados e interação com, no e pelo computador: estudos problematizados no AVEA Moodle sobre uso das tecnologias da informação e comunicação. Revista Novas Tecnologias na Educação, Porto Alegre, v. 10, n. 1, p. 1-11, 2012. 
BONA, M. F.; Redes sociais: O uso do Facebook em favor da aprendizagem. Revista educacional interdisciplinar, Taquara, v. 4, n. 1, p. 1-15, 2015.

BORBA, M. de C.; SILVA, R. S. R. da; GADANIDIS, G. Fases das tecnologias digitais em Educação Matemática: sala de aula e internet em movimento. Belo Horizonte: Autêntica Editora, 2014.

BORGES, J.F. O vídeo nas aulas de Geografia: uma proposta metodológica. Revista Educação, Marília SP, v.15, n.2, p.93-104, 2014.

BRASIL. Secretaria de Educação Fundamental. Parâmetros curriculares nacionais: geografia / Secretaria de Educação Fundamental. Brasília: MEC/SEF, 1998

CARVALHO, D.; BUENO, C. J. S.; PEDRO, K. M.; SILVA, E. G. Estudo sobre eficácia da aplicação de um objeto de aprendizagem com alunos do ensino fundamental. Revista Brasileira de Ensino de Ciência e Tecnologia, Ponta Grossa, v. 11, n. 1, p. 21-49, 2018.

CAVALCANTE, T. V.; FARIAS, J. F. Do local ao global: a utilização de tecnologias como ferramentas mediadoras do processo de aprendizagem na Geografia. Revista espaço acadêmico, Maringá, v. 10, n. 109, p. 89-94, 2010.

COSTA, M. J. M.; DUAILIBE, R. O.; JUNIOR, J. B. B. Metodologias ativas em sala de aula: o uso do Plickers no ensino de Geografia em uma escola da rede pública em São Luís, MA. Revista Tecnologias na Educação, Belo Horizonte, v. 27, p. 1-17, 2018.

DORNELlES, L. M. A.; FERREIRA, M. V. R.; PORTO, E. N. N.; CARVALHO, A. S. Alfabetização em GIS/SIG no ensino médio. Revista Didática Sistêmica, Rio Grande RS, v. 8, p. 257-268, 2008.

DORNELLES, L. M. A. SIG aplicado ao ensino de Geografia. Revista e-xacta, Belo Horizonte, v. 2, n. 3, p. 1-8, 2009.

FERREIRA, H. M. C.; COUTO-JUNIOR, D. R. Juventudes, educação e cidade: A mediação dos dispositivos móveis de comunicação nos processos de aprender-ensinar. Revista Textura, Canoas, v. 20, n. 44, p. 108-129, 2018.

FERREIRA, W. S.; LEITE, M. E. Tecnologias geográficas no Ensino Médio: Estudo de caso em escolas públicas de Montes Claros/MG. Revista Cerrados, Montes Claros, v. 15, n. 1, p. 330-350, 2017.

FRANCISCO, R. F.; BRAGA, A. C. O. Objetos de aprendizagem: Instrumentos para a avaliação formativa em educação a distância. Revista Científica de Educação a Distância, Santos, v. 13, n. 23, p. 1-20, 2020.

GIORDANI, A.; BEZZI, M. L.; CASSOL, R. Contribuição cartográfica através do objeto de aprendizagem decifrando os mapas. Revista Novas Tecnologias na Educação, Porto Alegre, v. 6, n. 1, 2008. 
HERPICH, F.; NUNES, F. B.; VOSS, G. B.; SINDEAUX, P.; TAROUCO, L. M. R.; Lima, J. V. Realidade Aumentada em Geografia: uma atividade de orientação no ensino fundamental. Revista Novas Tecnologias na Educação, Porto Alegre, v. 15, n. 2, p. 1-10, 2017.

KARWOSKI, A. C.; GRACIOLI, J. M. A. Tecnologias móveis e leitura de mapas digitais nas séries finais do ensino fundamental. Revista Teias, Rio de Janeiro, v. 21, n. 60, p. 282-295, 2020 .

LADEIRA, F. F. O uso do documentário "Derrubaram o Pinheirinho" para o estudo de conceitos de geografia urbana em uma turma de PROEJA. Revista Brasileira da Educação Profissional e Tecnológica, Natal, v. 1, n. 18, p. 1-14, 2020.

LIMA, H. H. N.; OLIVEIRA, A. A.; MESQUITA, A. A. Google Maps como instrumento didático-pedagógico no ensino da geografia: Um estudo de caso com os alunos do $6^{\circ}$ ano do ensino o fundamental do Colégio de Aplicação-CAP/UFAC. Revista Relato de Experiência, Rio Branco, v. 1, n. 1, p. 140-145, 2014.

MACÊDO, H.C. de; SILVA, R.O.; MELO, J. A. B. Oficina Pedagógica: uso de Geotecnologias no ensino de Geografia e as transformações na sociedade e reflexos na escola. Revista Geografia (Londrina), Londrina, v. 21, n. 2, p. 137-149, 2012.

MARTINS -JUNIOR, L. M.; ESTEVÃO, G. C.; MARTINS, R. E. M. W. Geografia e Google Earth na Sala de Aula: Proximidades, Diálogos e Aprendizagens. Revista Polyphonía, Goiânia, v. 31, n. 2, p. 105-120, 2020.

MEDEIROS, J. L. TECNOLOGIAS DIGITAIS E GEOGRAFIA: um relato de experiência. Revista Brasileira de Educação em Geografia, [S. 1.], v. 6, n. 12, p. 246-258, 2017.

MEDEIRO, L. M.; CONTI, V.; CANCELIER, J. W.; SILVA, J. P. M.; COLUSSO, P. R. Potencialidade do Google Maps nas aulas de Geografia em uma escola do campo. Revista Diálogo Educacional, Curitiba, v. 18, n. 58, p. 779-797, 2018.

MORAES, R.; GALIAZZI, M. do C. Análise textual discursiva. Ijuí: Unijuí, 2011.

OLIVEIRA, A. A.; MESQUITA, A. A. As tecnologias da informação como instrumentos didático pedagógicos no ensino da geografia: Uma experiência de formação com bolsistas PIBID no colégio de aplicação-UFAC. Revista Relato de Experiência, Rio Branco, v. 1, n. 1, p. 153-161, 2014.

OLIVEIRA, E. A. As Tecnologias Digitais de Informação e Comunicação (Tdics) e o Ensino de Geografia. Revista Educa Online, Recife, v. 11, n. 3, p. 71-84, 2017. 
OLIVEIRA, M. X.; BUFFON, E. C.; WERLANG, M. K. A utilização de objetos de aprendizagem no estudo do orvalho e da geada no $6^{\circ}$ ano do ensino fundamental. Revista Ciência e Natura, Santa Maria, v. 37, n. 4, p. 385-391, 2015.

OSTROVSKI C. S.; OSTROVSKI, D. Cinema no processo educativo. Educere - Revista de Educação UNIPAR, Umuarama, v. 9, n.2, p. 189-196, 2009.

OLIVEIRA, R. F.; KUNZ, S. A. S.; Tecnologias de Informação no ensino de geografia. Revista Geografia em Questão, Marechal Candido Rondon PR, v. 7, n. 2, 2014.

PASSOS, M. M. O professor de matemática e sua formação: análise de três décadas da produção bibliográfica em periódicos na área de educação matemática no Brasil. 2009. 328 f. Tese (doutorado) - Universidade Estadual Paulista, Faculdade de Ciências, 2009. Disponível em: <http://hdl.handle.net/11449/102016>. Acesso em:06 maio.2020.

PASSOS, A. M. Um estudo sobre a formação de professores de ciências e matemática. 2009. 139f. Tese (doutorado) - Universidade Estadual de Londrina, Centro de Ciências Exatas, 2009. Disponível em: http://www.bibliotecadigital.uel.br/document/?code=vtls000151196. Acesso em:06 maio 2020.

PEREIRA, A. M. O.; KUENZER, A. Z.; TEIXEIRA, A. C. Metodologias ativas nas aulas de Geografia no Ensino Médio como estímulo ao protagonismo juvenil. Revista do centro de Educação, Santa Maria, v. 44, p. 1-23, 2019.

PERINELLE -NETO, H.; PAZIANI, R. R. As interfaces entre linguagens audiovisuais e práticas pedagógicas em história e geografia: experiências, possibilidades e limites do curta metragem como uma "outra" compreensão do local e do vivido. Interfaces da Educação, Paranaíba, v. 3, n. 8, p. 48-58, 2012.

PERINELLI - NETO, H.; PAZIANI, R. R. Cinema, prática de ensino de história e geografia e formação docente: Produção de curtas-metragens - Experiências e Estudos de caso. Educação em Revista, Belo Horizonte, v.31, n. 4, p. 279-304, 2015.

RIZZATTI, M.; CASSOL, R.; BATISTA, N. L.; DAMBRÓS, G. Utilização de geotecnologias na cartografia escolar: A compreensão da representação do relevo com alunos do ensino fundamental. Revista Geografia em Questão, Marechal Candido Rondon, v. 10, n. 1, p. 56$76,2017$.

ROVANI, F. F. M.; DAMBROS, G.; QUOOS, J. H.; CASSOL, R. Objetos de aprendizagem para o ensino de geografia: Interação e animação com simuladores. Revista Novas Tecnologias na Educação, Porto Alegre, v. 10, n. 1, p. 1-11, 2012.

RUIS, L. S.; TAMARIZ, A. D. R.; BATISTA, S. C. F. Mobile games de entretenimento em práticas pedagógicas interdisciplinares. Revista Novas Tecnologias na Educação, Porto Alegre, v. 17, n. 1, p. 345-354, 2019. 
SANTOS, A. M.; FRANCO, T. F.; FARIAS, T. S. S.; SOUZA, D. L. L. "Aprender fazendo" Cartografias: Relatos de experiências através da extensão universitária. Revista Conexão UEPG, Goiás, v. 16, p. 01-13, 2020.

SANTOS-JÚNIOR, D.N.; LAHM, R.A. A. (re) construção da noção espacial através da tecnologia do sensoriamento remoto: o desenho, as imagens orbitais. Revista Renote - Novas Tecnologias na Educação, Porto Alegre, v.8, n.2, p.1-12, 2010.

SCHUCK, R. J.; CAZAROTTO, R. T.; SANTANA, E. L. Tecnologias Digitais de Informação e Comunicação (TDICs) no ensino de Geografia nos anos finais do Ensino Fundamental. Ensino em Revista, Uberlândia, v. 27, n. 3, p. 1131-1154, 2020.

SILVA, B. M. O Jogo Street Fighter II como Possibilidade de Análise da Paisagem Geográfica no Ensino de Geografia. Revista Polyphonía, Goiânia, v. 31, n. 2, p. 91-104, 2020.

SILVA, J. F.; SOLTAU, S. B.; Medindo o planeta Terra: Um experimento com abordagem interdisciplinar. Revista e-xacta, Belo Horizonte, v. 7, n. 1, p. 35-44, 2014.

SILVA, W. D. da. Geografia em jogo: algumas possibilidades de abordagens dos videogames na Geografia. Revista Ateliê Geográfico, Goiânia, v.10, n.1, p. 140-159, 2016

SOMMA, M. L. Alguns Problemas Metodológicos no Ensino de Geografia. In: CASTROGIOVANNI, A.C. (org.). Geografia em sala de aula: práticas e reflexões. 4.ed. Porto Alegre: Ed. UFRGS /Associação dos Geógrafos Brasileiros - Seção Porto Alegre, 2003.

TRENTIN, M. A. S.; SCOLARO, J. K. Ensino interdisciplinar das projeções cartográficas e suas relações com a matemática através de podcasts. Revista Debates em Educação, Alagoas, v. 10, n. 22, p. 303-315, 2018.

VOTTO, R.R.; RODRIGUES, E.F. O Cinema no ensino de Geografia: proposta de roteiro para trabalho em aula. Revista de Ensino de Geografia. Uberlândia, v. 8, n. 15, p. 206-224, jul./dez. 2017 